\title{
Uterine rupture at the fundus during pregnancy: a case report
}

\author{
Venkatesh K. V., Harsha B.* \\ Department of Obstetrics \& Gynaecology, Karnataka Institute of Medical Sciences, Hubli, Karnataka, India
}

Received: 25 September 2015

Accepted: 30 October 2015

\section{*Correspondence:}

Dr. Harsha B.,

E-mail: b.harsh29@gmail.com

Copyright: $\odot$ the author(s), publisher and licensee Medip Academy. This is an open-access article distributed under the terms of the Creative Commons Attribution Non-Commercial License, which permits unrestricted non-commercial use, distribution, and reproduction in any medium, provided the original work is properly cited.

\begin{abstract}
Rupture of a gravid uterus is a surgical emergency. Predisposing factors include a scarred uterus. Spontaneous rupture of an unscarred uterus during pregnancy is a rare occurrence. We hereby present the case of a spontaneous complete uterine fundal rupture at Karnataka Institute of Medical Sciences, Hubli, Karnataka, India. The patient had a history of septal resection. Spontaneous uterine rupture occurs when there is an upper segment uterine scar. This case report shows that past history of septal resection is a risk factor for the presence of uterine scar.
\end{abstract}

Keywords: Pregnancy, Uterus

\section{INTRODUCTION}

Ruptured uterus is an obstetric and surgical emergency that can lead to maternal or fetal death.

The maternal and fetal prognoses are most of the time bad especially if rupture occurred in an unscarred uterus. ${ }^{1}$ Uterine rupture happens usually during delivery, along the previous Caesarean scar. Uterine rupture can also occur, though rarely, on the upper uterine segment (corpus) as in the case of patients who have had a previous uterine rupture, classical caesarean section or uterine perforation. Spontaneous rupture of an unscarred uterus is very rare. We hereby report a case of spontaneous uterine rupture at 33 wks. Gestation in a patient who has had a septal resection.

\section{CASE REPORT}

A $28 \mathrm{yr}$ old female came to the labour room at $33 \mathrm{wk}$ gestation with a history of previous abortion with PV bleeding. Following abortion, she dint conceive for 3 yrs and underwent Diagnostic hysteroscopy for evaluation. Septate uterus was diagnosed and septal resection was done 2 yr back. On admission she had tachycardia and hypotension.

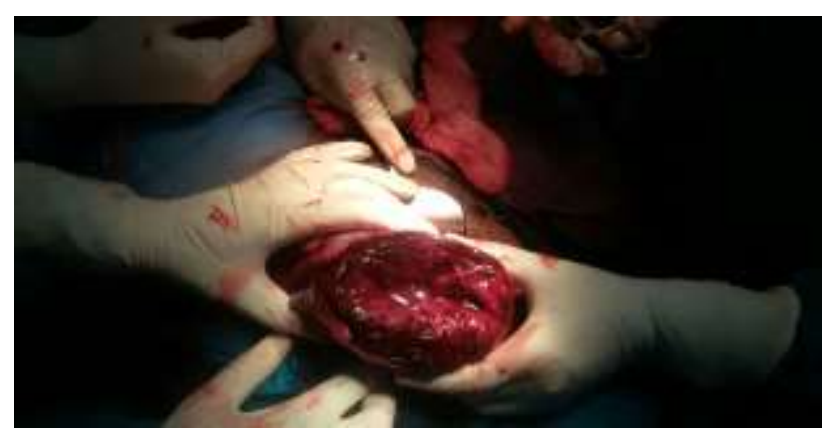

Figure 1: Uterine rupture at the fundus.

The abdomen was distended, uterine contour could not be made out and fetal heart sounds not heard. Vaginal examination showed clots. USG abdomen showed massive hemoperitoneum with FHR $<80 / \mathrm{min}$. Rupture uterus was diagnosed and taken for Emergency Laparotomy.

Intraoperatively, the uterus was ruptured at the fundus and fetus was extracted from the peritoneal cavity, which 
died after $10 \mathrm{~min} .1200 \mathrm{ml}$ of hemoperitoneum was drained. The rupture was repaired with continuous interlocking sutures using catgut 2;0. Anterior and posterior surfaces of uterus were intact. The patient was stable postoperatively, received 20 blood transfusions and was discharged on post-op day 12 .

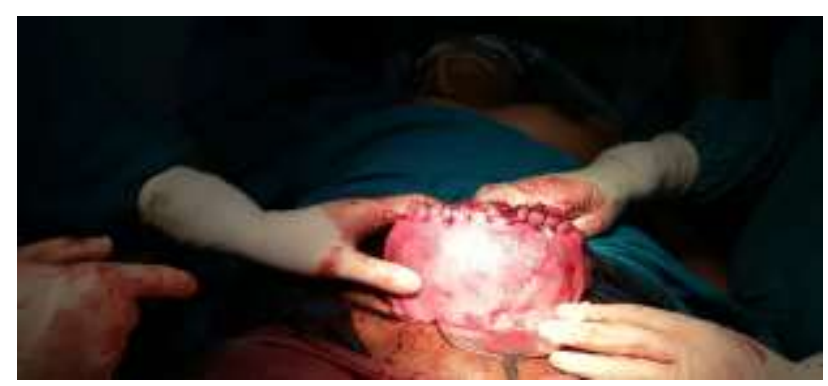

Figure 2: Sutured fundal rupture.

\section{Comments}

Rupture of a gravid uterus is one of the worst obstetric emergencies in which the life of both the mother and the child are in danger. The incidence ranges from between 0.2 to $0.6 \%$. $^{2}$

Factors that can predispose to uterine rupture are multiparity, advanced maternal age, a scarred uterus, mal presentation, a contracted pelvis, the misuse of oxytocic drugs, maneuvers like external cephalic or internal podalic version, instrumental deliveries, previous uterine surgeries like myomectomy and metroplasty. ${ }^{3}$ Uterine rupture can also occur without these factors.

Diagnosis of spontaneous uterine rupture during pregnancy occurring on a scarred uterus can be made by ultrasound scan in which case there can be protrusion of membranes at the site of the scar. The most common sign of uterine rupture on Cardiotocography is a nonreassuring fetal heart rate pattern with variable decelerations that evolve into late decelerations and finally bradycardia. ${ }^{3}$ In the case of late presentation as in our case, there are abdominal pains and signs of shock, at which time ultrasound scan will reveal an intraperitoneal pregnancy. In these cases the fetus is already dead and efforts are made to save the mother.

The incidence of rupture of an unscarred uterus varies between 1 in 10,000 to 1 in 15,000 Births. ${ }^{3}$ Most of them occur during labor and can even be due to the application of fundal pressure. Because the medical staff is not always prepared for the eventuality of a uterine rupture when there is no post-surgical scar and because of rapid bleeding in case of uterine rupture, the prognosis for both the mother and the child is very bad.

\section{CONCLUSION}

Uterine rupture occurring on an unknown scarred uterus is unpredictable and is associated with bad maternal and fetal prognosis. Patients with risk factors should be monitored during pregnancy and labour and rupture uterus should be suspected in the differential diagnosis of acute abdomen. Ultrasound scan and Cardiotocography should be carried out rapidly for early diagnosis and appropriate management.

\section{REFERENCES}

1. Ahmadi S, Nouira M, Bibi M, Boughi-Zane S, Sadi H, Chaib A. Rupture utérine sur utérus sain gravide. A propos de 28 case. Gynecol Obstet Fertil. 2003;31(9):713-7.

2. Nkwabong E, Kouam L, Takang W. Spontaneous Uterine Rupture during Pregnancy: Case Report and Review of Literature. African Journal of Reproductive Health. 2007;11(2):98-103.

3. Cunningham FG, Leveno KJ, Bloom SL, Spong CY, Dashe JS, et al. Obstetrical hemorrhage. In: Cunningham FG, Gant NF, Leveno KJ, Gilstrap III LC, Hauth JC, Wenstrom KD. Williams obstetrics. 24th ed. New York: McGraw-Hill. 2014;24:6178,790-2.

Cite this article as: Venkatesh KV, Harsha B.

Uterine rupture at the fundus during pregnancy: a case report. Int J Reprod Contracept Obstet Gynecol 2015;4:2072-3. 